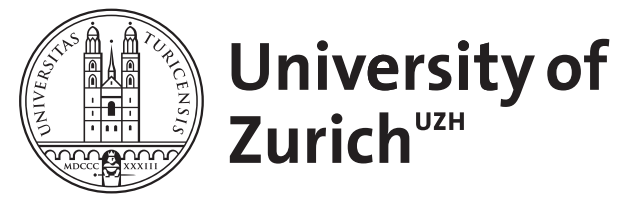

Zurich Open Repository and Archive

University of Zurich

University Library

Strickhofstrasse 39

CH-8057 Zurich

www.zora.uzh.ch

Year: 2011

\title{
Eugenio Coseriu, las tesis de Estrasburgo y el postulado de una linguiística lingüística
}

Kabatek, Johannes

Posted at the Zurich Open Repository and Archive, University of Zurich

ZORA URL: https://doi.org/10.5167/uzh-105344

Conference or Workshop Item

Originally published at:

Kabatek, Johannes (2011). Eugenio Coseriu, las tesis de Estrasburgo y el postulado de una lingüística lingüística. In: XIV Jornadas de Lingüística, Cádiz, 29 March 2011 - 31 March 2011. Servicio de Publicaciones de la Universidad de Cádiz, 35-56. 


\section{Johannes Kabatek}

Cátedra de Lingüística Románica

Universidad de Zúrich

Romanisches Seminar

Zürichbergstrasse 8

CH-8032 Zúrich (Suiza)

Tel. $+41-44-6343610$

kabatek@rom.uzh.ch

\section{Eugenio Coseriu, las tesis de Estrasburgo y el postulado de una lingüística lingüística}

Resumen:

La teoría del lenguaje de Eugenio Coseriu (1921-2002) presenta una impresionante coherencia y unidad desde sus concepción fundamental en los años 1950. Frente a la obra monumental (y en parte aún inédita) de aquella época, en los últimos años de su vida, Coseriu presentó en varias ocasiones textos muy cortos que en forma de principios o de tesis sintetizaban el fundamento esencial de su concepción del lenguaje. En esta contribución se presentará la versión tal vez más elaborada de este tipo de tesis, las Diez tesis a propósito de la esencia del lenguaje y del significado presentadas originalmente en francés en 1999 en el marco de un coloquio en Estrasburgo. Aparte de ofrecer una traducción al español del texto, se comentarán algunos de sus aspectos más destacados.

Palabras clave:

Eugenio Coseriu, Teoría del lenguaje, Filosofía del lenguaje, Historia de la lingüística, semántica, palabras y cosas, significado, texto.

\section{Introducción}

1.1. Entre los escritos de los últimos años de la vida de Eugenio Coseriu (1921-2002) coleccionados en el Archivo Coseriu de la Universidad de Tubinga (www.coseriu.de) se encuentra una serie de manuscritos de discursos y otros textos relativamente breves que resumen algunos de los aspectos más fundamentales de su obra ${ }^{1}$. Así, Coseriu explica en varias ocasiones cuáles fueron los principios fundamentales que guiaron su labor científica, destaca cuál fue, en su opinión, su aportación más importante a la

1 También hay una serie de aspectos personales que se tocan en algunos textos de los últimos años, así, encontramos una biografía personal de Coseriu en J. Kabatek / A. Murguía, „Die Sachen sagen, wie sie sind...". Eugenio Coseriu im Gespräch, Tübingen: Narr 1997, donde, además de la relación de Coseriu con diferentes lingüistas, también se habla de su postura frente al nacionalismo y de sus diferentes patrias. En La preghiera come testo (No. 359; versión española en no. 371), se ve, aparte de un análisis lingüístico-textual, la relación de Coseriu con la religión.

Los números que indicamos junto a los títulos de las obras se refieren a la lista bibliográfica de la página web del archivo Coseriu (www.coseriu.de). La mayor parte de los trabajos se pueden consultar en esa página directamente haciendo clic en el título correspondiente. 
lingüística y expone cuál debe ser el punto de partida para un planteamiento adecuado de las cuestiones lingüísticas. En lo que sigue me ocuparé sobre todo de este último aspecto, sin por ello dejar de mencionar brevemente de qué tratan los primeros dos.

El primero de estos tres aspectos es tratado en varios de los numerosos actos de investidura como doctor honoris causa y en otras ocasiones en las Coseriu recibió distinciones de diversa índole. Así por ejemplo, en la investidura como doctor h. c. de la Universidad de Granada que tuvo lugar en 19912, Coseriu enumera los siguientes cinco principios que guiaron su labor:

- el principio de la objetividad científica;

- el principio del humanismo o del "saber originario";

- el principio de la tradición;

- el principio del antidogmatismo;

- el principio del bien público o de la responsabilidad social.

El primer principio, el de la objetividad científica, será tratado más abajo, ya que vuelve a aparecer en el texto que aquí nos ocupará más en detalle. Es el principio correspondiente al lema coseriano-platónico Ta onta os estin légein ('Decir las cosas tal como son'), que supone, por lo menos como ideal y finalidad última del trabajo científico, tanto la posibilidad de acceso a las "cosas" como la posibilidad de nombrarlas de manera objetiva.

El principio del saber originario se refiere al postulado de una diferencia fundamental entre ciencias naturales y humanidades: en las ciencias del hombre, los objetos investigados no son ajenos a nosotros mismos, son productos de nuestra propia actividad y corresponden, entonces, a un saber originario de las cosas. La tarea del científico es aprovechar este saber originario, partir de él y objetivarlo, sin por ello confundirlo con el saber científicamente objetivo. Se rechaza, pues, la idea frecuentemente defendida por la lingüística actual de la necesidad de hipótesis arbitrarias y su verificación o falsificación: las hipótesis no son arbitrarias, sino derivadas de nuestro saber originario, y tratar el lenguaje como si fuera una sustancia química o un mineral no sería solo limitarnos inútilmente, sino pretender algo imposible, ya que somos incapaces de acceder al lenguaje sin al mismo tiempo estar condicionados por él.

El principio de la tradición impone el respeto por todo lo que se ha dicho y pensado en la historia de la humanidad: no se empieza a hacer lingüística ayer o hace diez años, los problemas que se plantean ahora se han planteado, aunque de otra forma, en diferentes momentos de la historia del pensamiento humano y hay que ser consciente de ello y buscar las soluciones adecuadas teniendo en cuenta aquellas que ya se han propuesto en otros momentos de la historia del pensamiento humano. Este principio está en estrecha relación con el anterior, ya que deriva de la continuidad del objeto y de la continuidad del saber originario: el lenguaje no era distinto en tiempos de Aristóteles y el saber originario del Estagirita no era otro que el de un lingüista actual. Frente a las ciencias naturales, donde la evolución técnica ha hecho descubrir objetos anteriormente desconocidos, el lenguaje sigue siendo lenguaje; las lenguas, lenguas y los hablantes, hablantes. Con lo cual no se quiere negar el avance de las ideas ni el avance de la disciplina, pero el avance solo es real si toma en consideración la tradición de esta; y a veces un supuesto avance vuelve a plantear ideas erróneas ya identificadas como tales y superadas en el pasado.

\footnotetext{
${ }^{2}$ Coseriu 1993a.
} 
El principio del antidogmatismo postula la absoluta libertad del pensamiento y una postura crítica frente a cualquier doctrina preconcebida: el investigador no debe partir de principios impuestos por otros ni seguir ciegamente las pautas de esta o aquella escuela. Es cierto que esto también vale para el rechazo de posibles ideas: no hay "religión" lingüística y no se nace siendo estructuralista, formalista o funcionalista, como tampoco se nace rechazando de antemano ninguna orientación. El lingüista debe cultivar su propia formación y tener el horizonte más amplio posible; debe criticar allá donde ha llegado a la convicción libre de que se halla ante el error, y defender aquellas ideas que, tras un examen crítico, son las que en mayor grado corresponden al primer principio, el de la objetividad.

Por último, el principio del bien público se opone a una ciencia desconectada de los problemas de relevancia social o del interés de las personas ajenas a la torre de marfil académica $^{3}$ : no se hace solo lingüística para los lingüistas, no hay derecho a la arrogancia frente a las preguntas que le hacen al lingüista los hablantes que quieren saber algo sobre el lenguaje o la lengua, ya que quieren saber algo sobre ellos mismos. El lingüista no tiene derecho a contestar: "tú no me vas a entender", tiene que ser capaz de escuchar y de responder, de aplicar, de ayudar en la medida de lo posible con su saber para que se pueda enseñar, traducir, interpretar, hablar, escribir y argumentar lo mejor posible. Y debe también criticar allá donde mediante el lenguaje se manipula, se miente o se tiraniza.

Estos principios Coseriu no solo los postula para la actuación propia; por ellos deberían guiarse también los lingüistas en general: son principios que a primera vista parecen simples y convincentes, pero que son en realidad incluso radicales y se oponen a varias de las corrientes dominantes en la lingüística contemporánea.

1.2. El segundo de los aspectos arriba mencionados se refiere a la cuestión de lo que Coseriu consideraba su aportación más importante a la lingüística, y se encuentra también en estrecha relación con lo que se presentará aquí: podríamos pensar que lo que Coseriu más apreciaba de su obra fuera la tripartición entre sistema, norma y habla o la de las dimensiones de las variedades; sin embargo, Coseriu repetía en distintas ocasiones que lo más importante para él fue algo mucho más general y, por lo menos aparentemente, muy simple: la diferenciación fundamental, expuesta en numerosas ocasiones, de tres niveles o planos diferentes del hablar, el universal, el histórico y el individual, cada uno considerable desde tres puntos de vista diferentes (actividad, saber y producto $)^{4}$. Esta diferenciación parece tan general que muchas veces es citada sin referencia a Coseriu. Ella refleja otras distinciones anteriores que encontramos en autores como Aristóteles, Guillermo de Humboldt, Georg von der Gabelentz, Ferdinand de Saussure, o Ángel Amor Ruibal ${ }^{5}$, pero adquiere en Coseriu una precisión particular y ocupa la posición central en todo su edificio de pensamiento lingüístico: todos los demás conceptos se elaboran y se ubican a partir de esta tripartición, encontrándose así anclados en una construcción ordenada con fundamento inalterable. Una vez establecido este fundamento, el postulado coseriano es que cada investigación lingüística debe siempre tener consciencia clara de su lugar concreto. La realidad de los estudios, sin embargo, confunde muchas veces los niveles; cuando, por ejemplo, se quiere hablar de una supuesta gramática universal y se está pensando, en realidad, en la gramática de una lengua particular o cuando, al revés, se está hablando de "pragmática de la lengua x"

\footnotetext{
${ }^{3}$ Véase una presentación exhaustiva de los principios en Coseriu 1993a.

4 Véase la tesis 6, más abajo, y lo expuesto en Coseriu 1992, p. 88 y ss.

${ }^{5}$ Acerca de este último, cf. Kabatek 2009.
} 
y se está en realidad hablando de pragmática sin más (es decir, universal) o de tradiciones discursivas no determinadas por la lengua $\mathrm{x}$, sino por una determinada tradicionalidad cultural. El fundamento epistemológico de los tres niveles guía tanto la producción científica como la recepción: en la producción, hay que evitar la confusión de estos niveles, y en la recepción, hay que señalar aquello que un estudio determinado es capaz o no es capaz de afirmar, sus alcances y límites - otro par de conceptos frecuentemente empleados por Coseriu-: hay que partir del supuesto, según el principio de la valoración simpatética, de que cada estudio arranca de la buena voluntad de un investigador de decir algo acertado sobre las cosas; y hay que señalar en qué medida el camino emprendido le permite alcanzarlo y en qué medida no.

1.3. Por último, el tercer aspecto de los arriba enumerados es, de algún modo, previo a los otros dos; es el más fundamental de los tres: de él deriva todo lo demás. Se trata de la concepción fundamental de lo que el lenguaje humano es. En este sentido, es el punto de partida no solo de la lingüística sino, siendo el lenguaje el fundamento de nuestro ser, de la esencia de lo humano. En esta concepción fundamental se refleja toda la base filosófica del pensamiento lingüístico coseriano, en particular, la marcada influencia del idealismo alemán de la época entre Herder y Humboldt, pero también el fundamento en la filosofía antigua y el desarrollo de la filosofía del lenguaje en los siglos XIX y XX. Si esta concepción se halla implícita en los trabajos de Coseriu desde la época uruguaya de los años cincuenta ${ }^{6}$, es en su formulación condensada en pocas tesis donde se encuentra de manera más densa y más compacta. Estas tesis fueron presentadas y publicadas en varias ocasiones ${ }^{7}$, siendo la versión más elaborada y, en nuestra opinión, más lograda la de las diez tesis enviadas a los participantes de un coloquio sobre Perception du monde et perception du langage celebrado en Estrasburgo en 1999. Presentaremos, a continuación, las diez tesis coserianas en su traducción al español y seguiremos después con un comentario breve acerca de ellas ${ }^{8}$.

\footnotetext{
${ }^{6}$ Coseriu mismo dice en varias ocasiones que fue la época montevideana la que da lugar a su concepción fundamental del lenguaje, como por ejemplo en Coseriu 1993a, 25: "En Uruguay he desarrollado mi teoría lingüística en todo lo esencial, de suerte que mucho de lo que he publicado después (y de lo que sigo publicando) procede de manuscritos, esbozos y notas de mi época uruguaya".

7 Una versión española se publicó en Chile en 2006 en la revista Literatura y Lingüística [373]; un texto más corto titulado "Tesis acerca del significado", de contenido parcialmente semejante, se publicó en 1998 en la revista Lexis [330].

${ }^{8}$ En vista de los manuscritos hallados en el Archivo Coseriu y habiendo aún presenciado personalmente el proceso de configuración del texto, me pareció oportuno no presentar la versión española publicada en 2006 sino una nueva traducción, realizada en colaboración con Mónica Castillo Lluch, del texto francés mandado a Estrasburgo en 1999. Para ella no nos basamos solo en las versiones ya publicadas en francés, sino en todo el material manuscrito y publicado. En la revista Energeia 4 (2013, www.energeiaonline.de) se publicó la traducción junto a los manuscritos.
} 


\section{Las Diez Tesis de Eugenio Coseriu}

Eugenio Coseriu

\section{Diez tesis a propósito de la esencia del lenguaje y del significado ${ }^{9}$}

Traducción de Mónica Castillo Lluch y Johannes Kabatek

\section{Prioridad absoluta del lenguaje}

El error fundamental de la mayoría de las teorías (o "filosofías") del lenguaje consiste en querer reducir el lenguaje a alguna de las otras facultades (o actividades libres) del hombre: al entendimiento (el pensamiento racional), al espíritu práctico o al arte, cuando lo cierto es que el lenguaje no se deja reducir a "otra cosa". El lenguaje -y Hegel fue quien se dio cuenta de ello- es una de las dos dimensiones esenciales del ser del hombre, siendo la otra el trabajo. El hombre es el único ser que, en el sentido propio de estos términos, trabaja y habla. Mediante el trabajo, el hombre se construye sin cesar un mundo apropiado a su ser físico, mientras que mediante el lenguaje se construye un mundo apropiado a su ser espiritual: un mundo pensable (el mundo de la experiencia sensible, aunque es representable, no es pensable). De ahí que el lenguaje sea "el acceso" a todas las posibilidades culturales del hombre (incluidos el pensamiento discursivo, la ciencia, la filosofía, la poesía). En este sentido, Hegel constataba que el lenguaje era "voreilig" ya que contiene de antemano todas las formas del desarrollo del espíritu. Todos los demás rasgos característicos del lenguaje derivan de este hecho fundamental. ${ }^{10}$

9 Este texto es una traducción del manuscrito que lleva el número A 350 en la clasificación del Archivo Coseriu (forma parte de los manuscritos que se añadieron posteriormente a la clasificación hecha en los años noventa y consultable bajo $<$ www.coseriu.de/klassif.htm>). El título de la versión original francesa es Quelques thèses à propos de l'essence du langage et du signifié. El texto fue originalmente enviado, en una versión previa, a los participantes de un seminario celebrado en Estrasburgo, del 7 al 10 de octubre de 1999, en el marco del coloquio Perception $d u$ monde et perception du langage. La versión enviada por Coseriu el 14 de octubre, así como los apuntes previos a esta versión se pueden consultar en la revista Energeia 4 (2013), véase www.energeia-online.de. Más tarde, el texto fue publicado dos veces, por un lado, en versión en línea, en la revista electrónica Texto (véase <http://www.revue-texto.net/Inedits/Coseriu_Theses.html >) y, por otro lado, en versión impresa, en Keller, D. / Durafour, J. P. / Bonnot, J. F. P. / Sock, R. (éds.): Percevoir: monde et langage. Invariance et variabilité du sens vécu, Sprimont: Mardaga 2001, p. 79-92. Intentamos reproducir el texto original de la manera más fiel posible, recomendando, en todo caso, tener en consideración el original francés. Existen otros textos afines, como los mencionados en la nota anterior, así como fichas en el Archivo Coseriu con apuntes de temática semejante, que hemos tenido en cuenta a la hora de preparar la traducción.

10 Esta idea y la referencia a Hegel es fundamental para la concepción del lenguaje de Coseriu y se encuentra repetidas veces a lo largo de su obra, cf. también el siguiente pasaje: "Es ist etwas anderes, wenn man sich fragt, was eine Interpretation der 


\section{Lenguaje y cultura}

El lenguaje es actividad creadora y, como tal, es actividad "cultural" infinita; pero al mismo tiempo es una forma de la cultura y la base de la cultura, en particular, en cuanto tradición cultural.

\section{Los universales del lenguaje}

El lenguaje se caracteriza por cinco universales -tres universales primarios: creatividad, semanticidad, alteridad, y dos universales secundarios o derivados: historicidad y materialidad-. La creatividad ('enérgeia') es característica de todas las formas de la cultura. Entre estas, el lenguaje es la actividad que crea significados, signos con significaciones, y de ahí su semanticidad. Sin embargo, estos signos son siempre creados "para el otro", o, mejor dicho, como si fueran ya de antemano del otro, y de ahí su alteridad. En este sentido, el lenguaje es la manifestación primaria de la alteridad: de ese "ser con el otro" característico del hombre. La historicidad resulta de la creatividad y de la alteridad, y significa que la técnica de la actividad lingüística se presenta siempre bajo la forma de sistemas tradicionales propios de comunidades históricas, sistemas que se llaman lenguas. Incluso lo que se crea en el lenguaje se crea siempre en una lengua. La materialidad, por su parte, resulta de la semanticidad y la alteridad: la semanticidad es un hecho de la mente y no sale de ella; para que pueda ser "para otro", tiene que estar representada en el mundo sensible por significantes materiales. Sin duda, sucede otro tanto con las demás actividades culturales, cuyos contenidos, como es sabido, se constituyen únicamente en la mente y deben todos estar "representados" en el mundo sensible. Aun así, la materialidad del lenguaje es diferente de la de las otras actividades culturales, ya que es siempre materialidad específica de una lengua. Así ocurre también con la historicidad de las otras actividades culturales, y de este modo, los "estilos" del arte no son análogos a las lenguas.

Sprache zur Interpretation des Menschen beitragen könnte. Da bin ich schon überzeugt, daß die Sprache gerade das Definitorische des Menschen ist und daß deshalb auch Hegel die Sprache nicht als eine Form des Geistes oder der Kultur ansieht, sondern als eine Dimension der Menschlichkeit, noch vor der Differenzierung des Geistes, und zwar neben der Arbeit. Die Sprache ist in der ewigen Idealgeschichte der Entwicklung des Menschen "voreilig", weil sie alles Geistige schon im voraus enthält, wenn auch als noch nicht differenziert. Sie ist - wie ich es einmal formuliert habe - das "In-Erscheinung-Treten des Menschlichen" und die "Eröffnung aller (geistigen) Möglichkeiten des Menschen". Deshalb nehme ich mit Hegel und mit Hegelscher Begründung eben die Arbeit und die Sprache als Grunddimensionen des Wesens des Menschen an. Die Arbeit für den Menschen als biologisches Wesen, die Sprache für den Menschen als denkendes Wesen. Beide Dimensionen können ihrerseits auf die ursprüngliche Negativität des Menschen zurückgeführt werden - auf den "luziferischen Charakter des Menschen" als eines Wesens, das die Welt nicht so annimmt, wie sie ihm gegeben ist, sondern die Welt ändert oder sich eine eigene Welt konstruiert, die für seine sich immer weiter entwickelnden Bedürfnisse geeignet ist, so daß die Welt des Menschen in beiderlei Hinsicht unendlich ist. Unendlich in biologischer Hinsicht, weil immer wieder neue Bedürfnisse geschaffen werden und neue Modifizierungen der naturgegebenen Welt stattfinden; unendlich im geistigen Bereich, weil das Denken und die Kreativität nie zu einem Ende kommen." (E. Coseriu en: Kabatek / Murguía 1997, 266). 
Obsérvese además que el lenguaje es la única actividad cultural definida por dos universales (semanticidad y alteridad), y no por uno solo, y que en él la alteridad se halla triplemente presente, ya que condiciona también la historicidad y la materialidad.

\section{Comunicación y comunidad}

El lenguaje (en cuanto decir), desde luego, es "comunicación". Pero hay que distinguir entre la comunicación de algo -hecho práctico y que puede también no darse sin que por ello el lenguaje deje de ser tal- de la comunicación con el otro, sin la cual el lenguaje ya no es lenguaje y que se da sin falta (está presente ya en la creación de los significados), pues corresponde a la alteridad fundamental del lenguaje. En lo que concierne a la comunidad, el lenguaje no es simplemente un "hecho social", un "producto" de la sociedad comparable a las "instituciones" sociales; es, bien al contrario (Aristóteles bien lo vio en su Politeia), debido a la alteridad, el fundamento de toda asociación humana.

\section{Nombrar y decir}

Las dos funciones fundamentales del lenguaje son el 'onomásein' y el ‘légein' (Platón): nombrar y decir (lo que más o menos corresponde a la distinción entre léxico y gramática). Pero mientras que en el "nombrar" (primario) todo es lenguaje (ya que se trata de la organización del mundo en categorías y especies), en el "decir" (donde se trata de establecer relaciones en este mundo y con este mundo), es solo la "forma" genérica -la modalidad semántica- de estas relaciones la que es propiamente "lenguaje" puesto que, en cuanto a su sustancia, el decir es también ciencia, actividad práctica, sentimiento, arte (poesía), etc.

\section{Contenido del "decir"}

En el contenido "expresado" y "comunicado" por el "decir", hay que distinguir entre designación, significado y sentido. La designación es la referencia a las "cosas" ("estados de cosas", "acontecimientos", "procesos") extralingüísticas (o, mejor, exteriores a los signos). El significado es la posibilidad objetiva de designación dada en los signos de una lengua. Por último, el sentido es la finalidad de cada "decir", el contenido propio de un discurso como tal (o de un fragmento de un discurso). Así, la constatación, la réplica, la respuesta, la pregunta, la objeción, el acuerdo, el desacuerdo, el ruego, etc. (todos los 'lógoi' de los estoicos) son unidades de sentido (y no de "significación"). Desde el punto de vista lingüístico, el sentido es la finalidad del discurso en cuanto que viene dado (expresado) por el significado (léxico, categorial, gramatical, "óntico") y la designación; pero a la constitución del sentido contribuyen también el conocimiento de las "cosas" y los "entornos". El contenido propiamente y exclusivamente lingüístico es, por consiguiente, el significado.

\section{Lenguaje y poesía}

Como identificación de una modalidad del ser, el significado es un acto de conocimiento, y, al igual que la poesía (y el arte en general), de conocimiento intuitivo concretamente. Esto ha conducido a ciertos filósofos a identificar lenguaje y poesía, por lo menos en cuanto a los actos primarios de creación. Aun así, el significado (y, por consiguiente, el lenguaje) no 
es idéntico a la poesía. Por un lado, el significado siempre es obra de un sujeto dotado de alteridad, mientras que la poesía (y el arte en general) es obra de un sujeto absoluto (que se presenta como absoluto). Por otro lado, el lenguaje como tal no es más que significado (léxico, categorial, gramatical, "óntico"), mientras que la poesía es un "decir" con su propia sustancia. Los filósofos que identifican lenguaje y poesía solo consideran el lenguaje como "decir" (y como "decir" de un sujeto absoluto). Nosotros postulamos, en cambio, la prioridad del lenguaje también frente a la poesía. Y esto no quita que el lenguaje poético sea el lenguaje en su plenitud funcional.

\section{Significado y ser}

El significado de un nombre (o, mejor dicho, el significado en cuanto nombre) es 'diacriticòn tês ousías' (Platón): delimitación -y, de ahí, constitución- de una modalidad (siempre virtual) del ser. En sí, el significado de un nombre siempre es universal ya que no nombra "entes" reconocidos como tales sino una posibilidad infinita del ser. No se halla al final, sino al principio de la constitución de una "clase" (la cual, con respecto al mundo "real", también puede ser una clase de un solo miembro conocido, por ejemplo sol, luna - o incluso una clase vacía). Por lo tanto, la designación no es lo primero y principal del lenguaje, sino un hecho secundario: es el hecho de asociar una "cosa" reconocida a un significado ya dado. El nombre propio es, en el lenguaje, un hecho secundario: es un nombre de identificación histórica de un ente dentro de una clase ya reconocida como tal.

\section{Significado, verdad y existencia}

El significado ( $y$, de ahí, el lenguaje como tal) no es ni verdadero ni falso: es anterior a la distinción misma entre verdadero y falso. Además, como no representa más que una modalidad virtual (una posibilidad) del ser, el significado es anterior a la distinción entre existencia y no-existencia (Aristóteles). Solo puede ser verdadero o falso el "decir" en cuanto proposición ('lógos apofánticos'). Del mismo modo, solo conociendo un significado se puede reconocer la existencia de entes designables que le corresponden. Esto es lo que llamo el "carácter deíctico" del lenguaje; un nombre "muestra" una modalidad del ser (o, mejor dicho, la constituye y la representa), pero no dice nada acerca de ella (los nombres derivados y los nombres compuestos, en cambio, contienen ya un "decir" o, desde el punto de vista lingüístico, cierta "gramaticalización").

\section{Lenguaje y "cosas"}

El lenguaje es lo que confiere el ser a las "cosas" y no una nomenclatura para clases de "cosas" ya reconocidas de antemano como tales. Obviamente, el lenguaje no crea los "entes", sino su "ser": los hace ser esto o aquello. Así, el lenguaje no crea los árboles, sino su "ser árboles" (y no, por ejemplo, ser plantas en general u otra especie cualquiera). De este modo, el lenguaje nos conduce hacia un mundo ordenado de "cosas". Delimitando las modalidades del ser, permite constatar o reconocer en el "mundo" entes correspondientes a esas modalidades y ofrece así la posibilidad de la búsqueda de las "cosas" mismas, y, por consiguiente, la posibilidad de nuevas delimitaciones, ahora sí "objetivas": reconocidas en el mundo mismo de las "cosas" y nombrables mediante nombres creados (o "términos"). 
Toda ciencia comienza necesariamente por las clasificaciones dadas en el lenguaje, pero no se detiene en estas clasificaciones. Es así como surge el "lenguaje técnico" (o "terminología"). Toda terminología (incluida la terminología de la "ciencia popular") es, en este sentido, lo contrario del lenguaje originario (no terminológico): va de la designación a la significación y nombra efectivamente clases reconocidas de antemano como tales. Con todo, el lenguaje técnico solo se puede constituir de manera secundaria, partiendo de las delimitaciones ya realizadas en y por el lenguaje no técnico.

\section{Breve comentario acerca de las diez tesis}

Podríamos, evidentemente, detenernos aquí, ya que podría pensarse que añadir más información a un texto que busca precisamente la reducción y la densidad es estropearlo. Sin embargo, me parece que un breve comentario podrá añadir alguna información útil sobre la posición que ocupan las tesis dentro de la obra coseriana así como dentro de la historia del pensamiento lingüístico en general. No procederé comentando tesis por tesis sino apuntando algunos aspectos fundamentales del pensamiento lingüístico aquí expuesto. En algunos casos, estos aspectos aparecen en más de una de las tesis.

\subsection{Una lingüística lingüística}

Las diez tesis resumen algunas de las ideas fundamentales del pensamiento coseriano: en la línea del estructuralismo y prácticamente en contra de todas las corrientes lingüísticas modernas, postula un logocentrismo radical, una lingüística lingüística ${ }^{11}$ cuyo centro es la lengua particular: no vamos, según Coseriu, de las cosas a la lengua sino de la lengua a las cosas. ¿Cómo hay que entender esto? ¿No es totalmente contraintuitivo? ¿No es una total exageración antropocéntrica, el mundo desde el lenguaje y no al revés? Parece que sí y parece que es aquí donde el pensamiento de Coseriu se muestra particularmente vulnerable frente a las tendencias recientes de las ciencias de la cognición y de la mayoría de las teorías del lenguaje actuales ${ }^{12}$. La

${ }^{11}$ Evidentemente, la construcción lingüística-lingüística ya es ambigua en español ya que se puede analizar, por la homonimia del nombre con el adjetivo, o bien como $\mathrm{N}+\mathrm{A}$ o bien como $\mathrm{N}+\mathrm{N}$ como en la intensificación del tipo café-café 'auténtico café". El español permite la técnica de la intensificación por reduplicación en varias clases de palabras $(\mathrm{N}+\mathrm{N}$ : café café; $\mathrm{V}+\mathrm{V}$ : comer comer, $\mathrm{A}+\mathrm{A}$ guapo guapo $)$. Se trata de una técnica que pertenece a la gramática del español oral, como a la gramática de otras lenguas románicas y a la del inglés (y por lo tanto a veces considerada universal), pero imposible en alemán y otras lenguas. Véase Kabatek 1992.

12 Frente a las tendencias actuales, nos podríamos incluso plantear la cuestión de si hoy en día una lingüística lingüística aún tiene sentido. La respuesta, dada desde una consciencia histórica de la evolución pendular de la lingüística y su vaivén entre épocas más bien universalistas y épocas más bien particularistas, debería ser, a primera vista claramente afirmativa: como desde la Antigüedad siempre ha habido fases en las que se consideraba como absoluta una de las dos tendencias, la simple continuidad del péndulo anuncia ya una fase de particularismo después del actual universalismo. Pero tal como en la economía se duda hoy en día de la validez de los movimientos circulares como principio infalible de evolución, también en la lingüística (y más en la lingüística que en otras áreas de las humanidades), la actualidad de los acontecimientos hace pensar que 
insistencia coseriana en el logocentrismo se ha criticado de múltiples maneras, a veces reprochándole una especie de hermetismo sapir-whorfiano y otras veces una cierta ceguera frente a la importancia de la Gestalt de los objetos. Sin embargo, creo que, por un lado, esta visión semasiológica del mundo es la peor comprendida del pensamiento coseriano y por otro lado, que es absolutamente crucial para la comprensión de la concepción esencial de lo que el lenguaje humano realmente es. En cuanto a lo primero, hay que insistir en que Coseriu de ningún modo niega la característica gestáltica de las $\operatorname{cosas}^{13}$ ni sigue las pautas de un relativismo lingüístico extremo à la Whorf (todo lo contrario: fue uno de sus más feroces críticos). Pero Coseriu se adhiere a lo que para él fue el verdadero logro fundamental en la historia de la filosofía del lenguaje; el salto dado por los filósofos alemanes de Herder a Humboldt (aquella "verdadera filosofía del lenguaje"), con un papel primordial de Herder (ya que es el primero en formular las ideas de la centralidad de la lengua), un papel muy destacado de Hegel (ya que fue el que más claramente formuló la centralidad de algunos aspectos fundamentales, como el de la alteridad y de la historicidad) y la culminación en Guillermo de Humboldt (ya que aquí se une la filosofía a una auténtica lingüística).

Pero ¿en qué consiste realmente este salto cuántico de la filosofía del idealismo alemán? ¿Qué hay en estos pensadores que no se encuentra en la filosofía anterior? Para Coseriu ${ }^{14}$, los factores que hay que mencionar en este contexto son básicamente dos; uno que podríamos llamar "externo" o sintomático y otro que es interno y esencial. El factor externo se refiere a la centralidad de la filosofía del lenguaje en el edificio de pensamiento defendido por los idealistas alemanes: más que nunca en la historia, a partir de Herder, el lenguaje es el punto de partida del pensamiento filosófico y no deja de serlo hasta la actualidad. El otro aspecto, el interno, se refiere al "descubrimiento" de la diversidad de las lenguas del mundo y a la importancia que se le da. Desde la Antigüedad, el hombre se define como zoon politikon mediante el logos; el logos es lo que hace humano al ser humano y lo que lo dota de libertad. La libertad es dada por el logos; es expresada mediante el lenguaje, y esto es uno de los mayores bienes del ser humano. Todo esto es conocido: se encuentra en las diversas declaraciones de los derechos del hombre, caracteriza al pensamiento ilustrado y marca la idéologie lingüística de la Revolución Francesa. Lo que es nuevo en Herder es que este logos no es el logos universal: es el logos de la lengua materna, de una lengua particular. Evidentemente a los idealistas alemanes les resultaba muy conveniente tener una concepción que permitiera destacar la importancia de la lengua particular, la lengua nacional, una lengua de una nación en construcción. Frente a los franceses de la Revolución, cuya lengua (la revolucionada, por supuesto) era simplemente la universalmente mejor, la más natural y la que no necesitaba de una distinción entre lenguaje (universal) y lengua (particular), la lengua alemana tenía que ser expresión del espíritu de la nación. Esta idea se ha llevado más allá de sus límites y al abuso; se asocia con el nacionalismo de

hay una ruptura profunda de las normas del juego histórico que podría llevar a la interrupción del círculo. Estas líneas se redactan en un momento de crisis ya prolongada de la economía española y de dudas acerca de la validez del principio de circularidad económica. Pero hay que advertir que estas dudas son también cíclicas y aparecen con regularidad en tiempos de crisis, y curiosamente se suelen borrar de la memoria una vez superados los tiempos difíciles. En este sentido, no perderé la confianza en que una lingüística lingüística tenga futuro.

13 Véase, sobre todo Coseriu 1990 [248].

${ }^{14}$ Cf. Coseriu, Eugenio (1993): Die deutsche Sprachphilosophie von Herder bis Humboldt, [Teil I], WS 1985/86; Nachschrift von H. Weber, Tübingen 1993. [B 23] 
Fichte y con exageraciones nacionalistas posteriores. Pero la crítica a lo que podríamos llamar los "efectos secundarios" de este pensamiento no justifica que se deshaga su núcleo filosóficamente serio, igual que los que argumentan que la concepción de la universidad defendida por Humboldt fue machista y elitista no contradicen el principio fundamental de la libertad de la enseñanza y de la investigación ${ }^{15}$.

Así pues, la idea fundamental de la primera tesis nada tiene que ver con una psicología colectiva de los pueblos o con una limitación de nuestro acceso al mundo desde una lengua particular. Pongamos por caso que las cosas son las cosas y que tienen su Gestalt y su forma particular. Pero, como también se afirma en las tesis 8 y 10, los signos lingüísticos no son idénticos a las cosas, a los entes. Ni son "nombres" dados a cosas ya preexistentes. Las cosas son las cosas y los signos lingüísticos nos permiten hablar acerca de las cosas. Pero los signos no son las cosas mismas, sino conceptualizaciones de las cosas; "formas" abstractas que varían de lengua en lengua: el acto de significación otorga un ser a las cosas. Los niños ven las cosas, pero las "conocen" a través del lenguaje, mejor dicho: a través de los signos de una lengua particular. También podríamos decir - y sería lo mismo - que los niños conocen los signos de la lengua particular mediante las cosas. Y el "ser" de las cosas es el "ser" del "nombre" de una lengua particular. Un "ser" negativamente definido: desde la diferencia frente a otros "seres". ¿Qué es una copa? ¿Este objeto que tengo en la mesa? ¿Qué me dice el objeto, esta copa, de lo que "significa" 'copa', es decir, del valor del signo 'copa' en la lengua española? Si un hablante de la lengua española me dice: esto es una copa y señala el objeto en la mesa, sé que algo hay en esa cosa que corresponde al "ser" copa, pero no sé exactamente qué es: mi hipótesis puede ser que copa sea un objeto de cristal, un objeto transparente, un objeto redondo, un objeto con un logotipo encima, un objeto trimembre, una bola cortada por la mitad, un objeto para beber, un objeto para brindar... A un hablante nativo esto quizá no le llama la atención, pues los hablantes nativos suelen identificar los objetos con los signos de una lengua. De ahí que fuera precisamente el auge del estudio comparativo de las lenguas y la traducción lo que llevó a los idealistas alemanes - filólogos, políglotas, traductores ellos mismos- a descubrir la diferencia fundamental entre las lenguas. A mí personalmente, la palabra copa no me resultó fácil al inicio: mi hipótesis fue que copa significaba algo como "vaso de cristal para vino"; más o menos lo que en alemán es Weinglas. Pero después me di cuenta de que las copas no necesariamente tenían que ser de cristal, que podían incluso ser de plata o de oro y que en realidad copa no se refería a ninguna materialidad como el alemán Glas (lo cual también era cierto para vaso, que podía ser de plástico, mientras que un Glas siempre es de vidrio y cuando es de plástico, solo puede ser Becher, que a su vez también puede ser de otros materiales). Evidentemente, no niego que tanto los alemanes como los españoles sabemos lo que es un vaso de plástico, una copa de cristal, una copa de vino, una jarra, un cubo y una garrafa, pero para comunicarnos tenemos que saber lo que significa vaso, copa, jarra, cubo o garrafa en la lengua española. Y esto vale

${ }^{15}$ De hecho, la concepción de la libertad de los idealistas alemanes también deriva fundamentalmente de su concepción del lenguaje: el hombre está, de algún modo, condenado a la libertad por el lenguaje. Ha perdido los instintos de los animales y su entorno natural en el que la comunicación funciona mediante estímulos y respuestas; pero el lenguaje, que le priva de los instintos, le permite sobrevivir precisamente por la libertad comunicativa que permite la adaptación a ámbitos no naturalmente destinados a la vida humana. Es interesante ver, en este contexto, que incluso la concepción de la libertad de un John Stuart Mill está fuertemente influenciada por el pensamiento alemán, en particular, por Herder, véase Forster 2010 y 2011. 
del mismo modo para verbos como traer y llevar, ir y venir, para las formas gramaticales y para todo lo que una lengua dice o puede decir o tiene que decir y otra no. ¿Por qué llamar al significado particular "ser" de las cosas? Porque la simple contemplación de las cosas no es conocimiento. El acto de conocer convierte entes en seres. Y conocer significa distinguir este objeto frente a otros, distinguir un $x$ de un $y$. Así, $x$ e $y$ ya no son entes, son "seres". Y no es que el ser de las cosas esté dado en los objetos mismos: las cosas no hablan. Puedo señalar un objeto y decir: ¡esto!, pero solo señalo entonces la ipsidad de ese objeto mismo. Pero en el momento que asocio el objeto con un signo no solo asociable a este, sino a otros objetos individuales, el objeto adquiere una identidad: se convierte en un ejemplar de una clase de objetos. Y la identidad no está en este objeto desde el objeto: está en la manera de concebirlo desde la lengua.

Ahora bien, esto parece que solo se refiere al proceso de aprendizaje. Pero más allá del aprendizaje, la cuestión del "ser" de las cosas también afecta a la concepción misma del lenguaje. Se opone al universalismo, según el cual las lenguas solo parametrizan algunos principios fundamentales y universales, es decir, eligen entre esta o aquella posibilidad. En todas las ramas de las teorías formales se ha visto la necesidad de ampliar la gama de posibilidades universales cada vez que se estudiaba una lengua nueva: es sintomático el caso de la teoría de la optimidad, que empezó con un número muy limitado de "restricciones", a partir de las cuales se pretendía explicar la gramática de cada lengua individual desde la gramática universal. Pero con cada fenómeno individual, las restricciones universales se ampliaban y actualmente el bosque de las restricciones es tan denso como el de los parámetros en la rama correspondiente de la Gramática Generativa. ¿Será que el problema yace en la imposibilidad de concebir las interminables diferenciaciones de las lenguas del mundo desde una serie de principios universales? ¿Y del hecho de que el conocimiento, también en lingüística, se adquiere a partir del lenguaje (en forma de una lengua determinada) y no desde los hechos universales?

\subsection{La nomenclatura "refinada" y las cosas}

La prioridad del lenguaje se refiere, pues, al "ser" de las cosas, no a los objetos como entes. Coseriu no niega un conocimiento de las cosas que, en cierta medida, es independiente del lenguaje. El conocimiento de las cosas es algo que también encontramos en el mundo animal y es filogenéticamente anterior al lenguaje. Pero hay un salto cualitativo entre un conocimiento prelingüístico de los objetos - de saber, por ejemplo, que beber aquel líquido que brota de una fuente quita la sed- al "ser" agua, fuente, sed. La pregunta del ser hablante no es "¿cómo se llama el líquido que brota de la fuente?", sino "¿qué es lo que se llama (es decir, lo que los demás llaman) agua?". Parece aquí que estamos ante un objeto de la naturaleza que tiene una existencia objetivamente dada y que la tarea del lenguaje no es más que darle un nombre al objeto ya existente. Pero el principio derivado de casos como el de la "copa" arriba citado vale para los significados en general y no hay, en principio, significados "más universales" frente a significados "menos universales": lo que hay son objetos más o menos universalmente conocidos y signos más o menos fácilmente traducibles.

Las cosas sin el lenguaje no tienen, pues, existencia reconocible y comunicable; tienen existencia en cuanto objetos, pero no son "seres" en cuanto signos lingüísticos identificables. Sabemos que ya en la interpretación de Saussure (el Saussure del Cours), 
la insistencia en que las lenguas no son nomenclaturas ${ }^{16}$ contrasta con los gráficos en los que parece que los significados (el arbolito, el caballo) son cosas. Sin entrar en la difícil cuestión del origen real saussureano de los dibujos y de lo que Saussure realmente quería decir ${ }^{17}$, hay que insistir en que la idea fundamental del signo lingüístico como claramente diferenciado de la chose coincide con la concepción coseriana. Ahora bien, como el hecho de que los signos lingüísticos no son signos de nomenclaturas ya dadas es obvio y se puede mostrar con interminables ejemplos de la comparación de cualquier par de lenguas, en vastos ámbitos de la lingüística se defiende -implícita o explícitamente - una visión refinada de la relación entre lenguaje y cosas; la que acepta la diferencia fundamental entre objetos y signos lingüísticos, remediando el desfase con la supuesta existencia de una serie de características gestálticas de las cosas que permiten diferentes tipos de significación ${ }^{18}$. Nuestro conocimiento sensomotor establecería entonces, en un primer paso, una preordenación de los objetos, sobre la base de la cual las lenguas particulares con sus signos elegirían sus respectivas priorizaciones y categorizaciones; así, los hablantes del español llegarían a la distinción, por ejemplo, de vasos y copas mientras que los hablantes del alemán distinguirían, de manera diferente, Gläser y Becher. En algunos casos, esta idea parece convencer claramente si pensamos, por ejemplo, en las partes del cuerpo y las lenguas que distinguen pie y pierna frente a lenguas que no hacen tal distinción: todos los humanos tendríamos una idea gestáltica de pie, pierna, rodilla, tobillo etc., la cual en algunas lenguas llegaría a un tipo de categorización y en otras a otro ${ }^{19}$.

Por muy convincente que esto suene, sigo insistiendo -y creo que de acuerdo con Coseriu- en que me parece una conceptualización equivocada. Lo que hay que precisar es que evidentemente no queremos negar un conocimiento sensomotor de las cosas ni pretender que las cosas sean creadas por el lenguaje, como si sin lenguaje fuéramos animales ciegos perdidos en un mundo de cosas irreconocibles. La necesidad de

${ }^{16}$ Como es sabido, Saussure (1916/1984, 97s.) empieza la primera parte de los Principios generales del Cours precisamente con la crítica de la idea de la lengua como nomenclatura. Aun así, aduce ejemplos y gráficos que presentan una vue simpliste que invita a una visión contraria a lo que se dice en el texto. Cf. también Kabatek 2012.

17 Cf. Willems 2005.

18 Para lo que sigue, cf. Kabatek 2003.

19 "A los tres errores ya señalados, se agrega a menudo el de pretender encontrar las mismas categorías - el mismo "pensamiento lógico" - en todas las lenguas. Este error se manifiesta, en el campo teórico, en el postulado de una "lengua lógica ideal", de la cual las lenguas históricas serían copias más o menos imperfectas, y, a veces, como identificación de esa "lengua ideal" con una lengua histórica determinada, por ej., la griega o la latina. Y en el campo práctico el mismo error se manifiesta en la aplicación de las categorías de una lengua a otras lenguas que tienen categorías distintas: es lo que ocurre, por ej., cuando se habla de "dativo" o "ablativo" en la gramática española, o cuando se describe el guaraní según los esquemas de la gramática latina. Pero la verdad es que no existen otras lenguas que las históricas (puesto que las lenguas son por definición objetos históricos [...]), y que éstas presentan esquemas formales (y semánticos) diversos, y no son ni lógicas ni ilógicas [...]. Puede aceptarse que 'les langues représentent l'utilisation pratique des procédés du langage', o que 'las lenguas son variaciones sociales e históricas sobre el gran tema humano del lenguaje'; mas esto no significa ni que los procedimientos deban ser los mismos en las varias lenguas, ni que las lenguas históricas deberían reflejar una "lengua-idea". Las categorías lingüísticas tienen universalidad conceptual, y no generalidad histórica." (Coseriu ms). 
construir, más allá de la percepción sensomotora, un mundo de "seres" deriva de la imposibilidad de comunicarnos mediante las cosas. Es la construcción de su ser como acto histórico-comunitario la que permite hablar de las cosas, comunicarnos, y más: permite reconocer las cosas más allá de su pura apariencia física.

En este sentido, el pensamiento de Coseriu se opone radicalmente a las corrientes dominantes de la lingüística actual. Incluso llega a afirmar que el acto de nombrar es la esencia del lenguaje, no la comunicación o el decir (tesis 5). No se trata aquí, como se podría pensar en una visión superficial, de una preferencia personal del semanticista léxico Coseriu frente a otras, como la del sintacticista Chomsky. Se trata de una convicción de que lo que caracteriza esencialmente al lenguaje humano (en su forma de lengua particular) es precisamente la "organización del mundo en categorías y especies" (tesis 5). En este sentido, los tres universales primarios, creatividad, semanticidad y alteridad, son los que caracterizan el lenguaje humano, y no la recursividad ni ciertas generalidades empíricas ("universales" en el sentido de Greenberg) ${ }^{20}$. El salto evolutivo del que hablan Hauser, Chomsky y Fitch (2002) ${ }^{21}$ y que en una argumentación puramente circular atribuye a la recursión el papel fundamental que distingue a los humanos de los animales parece ser un hecho, pero tal salto no se da porque los humanos dispongan de un sistema computacional recursivo, sino porque son capaces, como queda expresado en la tesis 5, de desvincular el lenguaje de las cosas mediante la abstracción de los significados de una lengua.

\subsection{El diálogo}

Hay que precisar que la diferencia expresada en las tesis 4 y 5 no se debe malentender en un sentido monológico de la esencia lingüística: si en la tesis 4 se dice que la comunicación de algo no es más que un "hecho práctico que puede también no darse sin que por ello el lenguaje deje de ser tal”, es porque la posibilidad de la comunicación de algo deriva de un hecho primario, de la creación de los significados en sintonía con el otro. El lenguaje como tal - y esto deriva del principio universal de la alteridad- es, en su esencia, creación de signos de acuerdo con el otro, como ya apuntaba $\mathrm{Hegel}^{22}$.

En este sentido primario del conocimiento del ser de las cosas como conocimiento solidario con una comunidad de hablantes, con una historicidad inherente, el lenguaje es

20 Cf. Kabatek 2012.

${ }^{21}$ Nótese lo absurdo que es contar citas y derivar de su frecuencia la importancia de algo: he citado este artículo en varias ocasiones para insistir en el desacuerdo total de una argumentación llena de prejuicios y de circularidades. Se postula en este trabajo que la recursión es lo que define al lenguaje humano y se postula un salto evolutivo a partir del cual hay recursión. Lo de la recursión no se cuestiona, se adopta simplemente porque corresponde al dogma chomskiano reinante. No parece importar ni que haya recursión también en el mundo animal ni que la recursión no tenga nada que ver con la esencia del lenguaje, ya que el lenguaje es tal también sin estructuras recursivas (aunque también dudamos que existan lenguas sin estructuras recursivas, cf. Kabatek 2012). Tampoco parece haber lenguas sin vocales, pero una lengua sin vocales podría ser, aunque fisiológicamente incómoda, perfectamente lengua).

22 "Denn sie [die Sprache] ist das Daseyn des reinen Selbsts, als Selbsts; in ihr tritt die für sich seyende Einzelheit des Selbstbewusstseyns als solche in die Existenz, so dass sie für Andere ist." G. W. F. Hegel, Phänomenologie, VI, B, Ia (Pues ella, la lengua, es el ser del yo en cuanto yo puro, es en ella donde la soledad aislada de la consciencia del yo se vuelve existencia de tal manera que exista para otros) 
dialógico en su esencia. Y es dialógico hasta en el monólogo, que es siempre un hablar con un ficticio $t u^{23}$. La alteridad como hecho esencial y universal opone la postura de Coseriu a una concepción del lenguaje como "hecho social" exterior al individuo (tesis $4)^{24}$, al mismo tiempo que la opone a las ramas de la lingüística que conciben una lengua como algo autónomo y supuestamente existente en una abstracción independiente de los individuos hablantes ${ }^{25}$.

\subsection{El texto y las tradiciones discursivas}

3.4.1. Como se ha dicho arriba (1.2.), la distinción de tres niveles del hablar (universal, histórico, individual) es fundamental para todas las cuestiones relativas al lenguaje. La tesis 6 resume brevemente los accidentes principales de estos niveles: designación, significado y sentido. En el famoso trabajo Determinación y entorno, de 1955-5626 Coseriu describe las tareas de una lingüística del hablar, de la universalidad lingüística. $\mathrm{Al}$ nivel histórico se refiere tanto en la distinción entre sistema, norma y habla ${ }^{27}$ como en los trabajos sobre variación lingüística y los numerosos trabajos de descripción estructural (como aquellos que se ocupan de la semántica estructural). Del nivel del texto, por último, se habla en la Lingüística del texto ${ }^{28}$ y en trabajos sobre poesía y estética.

La diferenciación de los niveles parece muy clara, por un lado, pero por otro lado ha habido, en los últimos años, una serie de discusiones acerca de la ubicación en el edificio coseriano de ciertos fenómenos que han entrado en el foco del interés de los investigadores recientemente. Tal es el caso tanto de la cuestión de una posible "universalidad del texto" como de la noción de las tradiciones discursivas.

3.4.2. En cuanto a la universalidad del texto, ya en 1997, Maria Selig afirmó que Coseriu tendría que haber incluido la noción de texto también en el nivel universal para hablar de las dimensiones pragmáticas del texto ${ }^{29}$. Poco después, Brigitte Schlieben-Lange habla de la universalidad del nivel individual ${ }^{30}$. Y en los últimos años, es sobre todo

23 Tú, que me lees, me entiendes, ¿verdad?

${ }^{24}$ En varias ocasiones desde los años 1950 Coseriu criticó la idea de Durkheim del fait social y su adopción en lingüística hecha por Saussure.

${ }^{25}$ En este sentido, Coseriu también se opone a la investigación del cambio lingüístico como algo independiente de los hablantes. Frente a la mano invisible de Rudi Keller (otro autor al que citamos negativamente a menudo), hay que considerar el cambio lingüístico siempre desde la actividad de los hablantes: así entendido, el cambio lingüístico no es sino un aspecto del hablar. Cf. Coseriu 1958 y 1983 [209].

26 Coseriu 1955-56 [21].

27 Coseriu 1952 [8].

28 Versión española: Coseriu 2007.

29 "Coseriu hat auf der universellen Ebene nur die sprachlichen Dimensionen kommunikativen Handelns berücksichtigt. Der Begriff 'Text' taucht bei ihm erst auf der Ebene der individuellen punktuellen Kommunikation auf. Mir scheint der Begriff 'Text' aber auch auf der universellen Ebene notwendig zu sein, dann nämlich, wenn es wie hier um universelle Phänomene geht, die nicht an die sprachlichen Dimensionen eines Textes, sondern an dessen Handlungsdimensionen anknüpfen" (Selig 1997, 206).

30 "on pourrait constater l'émergence de stratégies discursives très générales qui visent à l'autonomisation du texte écrit ou, à l'invers, à la contextualisation. Les phénomènes que nous avons traités appartiendraient aux stratégies d'autonomisation. Il en résulte la 
Óscar Loureda quien postula, en diferentes lugares, una tripartición del nivel individual, distinguiendo una dimensión universal del texto, una dimensión histórica y una dimensión individual ${ }^{31}$. Ya dijimos en otro lugar (Kabatek 2005, 26) que es obvio que tanto los fenómenos históricos como los fenómenos universales se pueden derivar de los textos, ya que de hecho los textos son la única manifestación concreta tanto del hablar en general como de la lengua. Sin embargo, la tripartición tiene precisamente el objetivo principal de señalar la diferencia entre los tres niveles y por eso no empieza con lo individual sino con lo universal para decir qué es lo que corresponde a ese nivel; sigue con lo histórico para describir lo exclusivo de ese nivel, y acaba con lo individual para explicar todo lo que corresponde al sentido de los textos. Con todo, parece que Coseriu mismo identifica claramente la universalidad del texto cuando habla, en la tesis 6, de la finalidad del discurso y los lógoi de los estóicos. Podríamos hablar también de la universalidad de los actos de habla, que no es una universalidad anterior a los textos, sino una universalidad de los textos ${ }^{32}$.

3.4.3. En 1988, Peter Koch presenta por primera vez el término de Tradiciones discursivas para añadir al edificio coseriano una segunda dimensión histórica al lado de la de las lenguas ${ }^{33}$. El término se refería a la historicidad de los textos; al hecho de que los textos, las formas textuales, los géneros y los modos de decir se repiten y que el hablar no consiste solo en la construcción de textos sobre la base de un léxico y de reglas gramaticales de una lengua. Hablar es también volver a decir lo ya dicho, manteniendo la tradición o alterándola. La noción de las Tradiciones discursivas ha tenido un enorme éxito en los últimos años, sobre todo porque la mayor parte de las diversas corrientes lingüísticas la habían excluido y porque hay muchos fenómenos que no se pueden explicar sin recurrir a la cuestión de la tradicionalidad de los textos. El éxito ha sido notable especialmente en los estudios históricos, pero también se observa cada vez más que la tradicionalidad textual tiene una enorme importancia también en ámbitos como la pragmática o la sociolingüística.

Pero mientras Peter Koch y Wulf Oesterreicher proponen duplicar el nivel histórico ${ }^{34}$, otros autores como Franz Lebsanft insisten en que las tradiciones de los textos tienen que ubicarse en el nivel individual, reservado, según la objeción de Koch, al enunciado en su pura individualidad, fenómeno, según él, fuera del interés del lingüista, que busca las regularidades y que considera lo individual solo por ser ejemplo más o menos representativo de lo que se repite.

Soy de la opinión de que también en este conflicto nos ayuda la idea defendida por Loureda de considerar el texto bajo tres aspectos y de que las tradiciones discursivas se refieren precisamente a la dimensión histórica del texto. Esta dimensión - la de los géneros, las formas textuales, la repetición de fórmulas, etc.- parece tener una historicidad parecida a la historicidad primaria de las lenguas y Koch/Oesterreicher la colocan por lo tanto al lado de la historicidad de las lenguas. Sin embargo, como ya hemos dicho en diferentes ocasiones ${ }^{35}$, la historicidad de los textos está en otro plano y es una historicidad secundaria frente a la historicidad primaria de la lengua. Creo

question troublante si on peut maintenir la distinction entre les niveaux du parler et du discours/texte" (Schlieben-Lange 1998, 269).

31 Vid., entre otros, Loureda Lamas 2005.

${ }^{32}$ Acerca de la cuestión de la universalidad de los actos de habla, cf. Kabatek 2005b.

33 Koch 1988. El término aparece por primera vez en el texto no publicado de Koch 1997.

34 Véase Koch 1997; Oesterreicher 1997; Koch/Oesterreicher 2012.

35 Véase entre otros Kabatek 2005b y 2014. 
encontrar en las diez tesis de Coseriu un claro apoyo a esta visión de las cosas: la historicidad primaria de la lengua histórica no es accidental; no nos servimos de ella para expresar algo tal como lo hacemos con una determinada forma textual. Podemos expresar algo mediante una carta, un soneto, una fórmula de saludo o un artículo científico. Pero aunque nos servimos de las formas textuales, no nos servimos de la misma manera de una lengua ${ }^{36}$. El nombrar, ese acto de alteridad que nos permite ver el "ser" de las cosas, es anterior a todo lo demás y fundamental para todas las tradiciones secundarias; las tradiciones discursivas son comparables a otras tradiciones culturales como la moda, la arquitectura, los géneros del arte, etc.: son tradiciones a los que el individuo se puede referir una vez que ha llegado al conocimiento del "ser" de los objetos. Lo único que nos confunde en el caso de las tradiciones discursivas es que su material es lengua, como lo es también el "material" del conocimiento primario. Pero hay que distinguir entre estas palabras en cuanto ejemplos de una lengua, que son palabras escritas en lengua española (nivel histórico), y este texto en cuanto ejemplar de una tradición, que es un ensayo para un libro científico (nivel de tradición discursiva), y este texto en cuanto individuo (nivel individual), que pretende comentar las diez tesis de Coseriu que forman parte de él y explicar, en estos pasajes, la diferencia entre historicidad primaria y secundaria.

\section{Final}

La bibliografía de Eugenio Coseriu es enormemente amplia, tanto cualitativa como cuantitativamente. Si añadimos a la obra publicada los numerosos escritos que yacen en las carpetas del archivo Coseriu, nos encontramos ante un saber cuasi enciclopédico y ante una producción enormemente variada y rica. Con todo, creo que lo más extraordinario de dicha obra no es ni la cantidad ni la variedad de temas tratados (que podría ser solo testimonio de mucho trabajo), sino su enorme claridad y su "forma interior" tan precisa y clara. Todo el edificio coseriano deriva de una serie de principios esenciales muy condensados, principios prácticamente inalterados a lo largo de toda su vida científica; modos de construcción que se presentan de manera altamente concentrada en las diez tesis aquí presentadas. En la enorme amplitud de la obra de Coseriu, estas tesis surgen como un lema que subyace a todo. A partir de ellas se invita al lector a descubrir un vasto mundo de lecturas, de conocimiento y un modo de pensar.

\section{Bibliografía}

(los números entre corchetes tras las obras de Eugenio Coseriu se refieren a la lista de publicaciones en www.coseriu.de):

Coseriu, Eugenio (1952): Sistema, norma y habla (con un resumen en alemán), Montevideo. [No. 8]

Coseriu, Eugenio (1955-56): "Determinación y entorno. Dos problemas de una lingüística del hablar", Romanistisches Jahrbuch 7, 24-54. [No. 21]

\footnotetext{
${ }^{36}$ Es cierto que decimos que nos servimos de lenguas cuando subrayamos los fines puramente comunicativos de una lengua. Pero antes de este hecho, antes de la comunicación (tesis 4), está el nombrar primario; el conocimiento del ser de las cosas mediante los signos de una lengua.
} 
Coseriu, Eugenio (1992): "Linguistic Change Does not Exist", Linguistica nuova ed antica, Anno I, Galatina, 51-63. [No. 209]

Coseriu, Eugenio (1990): "Semántica estructural y semántica cognitiva", in: Jornadas de Filología [Homenaje al Prof. Francisco Marsá], Barcelona, 239-282. [No. 248]

Coseriu, Eugenio (1992): Competencia lingüística. Elementos de la teoría del hablar, Madrid: Gredos. [No. 258]

Coseriu, Eugenio (1993a): "Discurso pronunciado con motivo de su investidura como doctor honoris causa", in: Discursos pronunciados en el acto de investidura de doctor honoris causa del Excelentísimo Señor Eugenio Coseriu, Granada: Universidad de Granada. 21-35. [No. 275]

Coseriu, Eugenio (1993b): Die deutsche Sprachphilosophie von Herder bis Humboldt, [Teil I], WS 1985/86; Nachschrift von H. Weber, Tübingen1993. [No. B 23]

Coseriu, Eugenio (2007): Lingüística del texto. Introducción a la hermenéutica del sentido. Edición, anotación y estudio previo de Óscar Loureda, Madrid: Arco Libros. [No. 375]

Coseriu, Eugenio (ms): Teoría lingüística del nombre propio, manuscrito, Montevideo (ed. en preparación por María Xesús Bello Rivas y Johannes Kabatek).

Forster, Michael Neil (2010): After Herder, Oxford: Oxford University Press.

Forster, Michael Neil (2011) German Philosophy of Language from Schlegel to Hegel and Beyond, Oxford: Oxford University Press.

Hauser, Marc D., Chomsky, Noam, Fitch, W. Tecumseh (2002): "The Faculty of Language: What Is It, Who Has It, and How Did It Evolve?", Science 298, 1569-1579.

Kabatek, Johannes (1992): "Mero mero (Aspectos de la reduplicación en el español hablado)", in: Hispanorama 61, 153-155.

Kabatek, Johannes (2003): "Unidad del significado, Designado y Lingüística Integral", Odisea 3, 87-99.

Kabatek, Johannes (2005a): Die Bolognesische Renaissance und der Ausbau romanischer Sprachen. Juristische Diskurstraditionen und Sprachentwicklung in Südfrankreich und Spanien im 12. und 13. Jahrhundert, Tübingen: Niemeyer

Kabatek, Johannes (2005b): "Sobre a historicidade de textos", Linha d'água (São Paulo) $17,159-170$.

Kabatek, Johannes (2009): "Fontes e contexto europeo da lingüística segundo Amor Ruibal, in: Andrés Torres Queiruga / Antonio Domínguez Rei / Pablo Cano López (eds.): Amor Ruibal, Filólogo, Santiago de Compostela: Consello da Cultura Galega, 193-217.

Kabatek, Johannes (2012): “Intuición y empirismo”, in: Martínez del Castillo, Jesús (ed.): Eugenio Coseriu (1921-2002) en los comienzos del siglo XXI, Analecta Malacitana, Anejo LXXXVI, 99-115.

Kabatek, Johannes (2014): “Warum die 'zweite Historizität' eben doch die zweite ist von der Bedeutung von Diskurstraditionen für die Sprachbetrachtung", in: Lebsanft, Franz / Schrott, Angela (eds.): Diskurse, Texte, Traditionen. Methoden, Modelle und Fachkulturen in der Diskussion, Bonn: Bonn University Press / Vandenhoeck\&Ruprecht, 11-25.

Kabatek, Johannes / Adolfo Murguía (1997): „Die Sachen sagen, wie sie sind.... Eugenio Coseriu im Gespräch, Tübingen: Narr.

Keller, Rudi (1994): Sprachwandel. Von der unsichtbaren Hand in der Sprache, Tübingen, Francke, 21994 (11990).

Koch, Peter (1987): Distanz im Dictamen. Zur Schriftlichkeit und Pragmatik mittelalterlicher Brief- und Redemodelle in Italien, Freiburg im Breisgau, ms. no publicado. 
Koch, Peter (1988): "Norm und Sprache", in: Energeia und Ergon. Studia in Honorem Eugenio Coseriu, ed. por Jörn Albrecht, Jens Lüdtke y Harald Thun, vol. II, Tübingen, 327-354.

Koch, Peter (1997): “Diskurstraditionen: zu ihrem sprachtheoretischen Status und ihrer Dynamik", in: Frank, B./Haye, T./Tophinke, D. (eds.), Gattungen mittelalterlicher Schriftlichkeit, Tübingen, Narr, 43-79.

Lebsanft, Franz (2005): “Kommunikationsprinzipien, Texttraditionen, Geschichte" in: Angela Schrott / Harald Völker (eds.): Historische Pragmatik und historische Varietätenlinguistik in den romanischen Sprachen, Göttingen: Universitätsverlag Göttingen, 25-43.

Loureda Lamas, Óscar (2005): “El texto según Eugenio Coseriu”, in: Jesús Gerardo Martínez del Castillo (ed.): Eugenio Coseriu, in memoriam, Granada: Granada Lingüística, 101-122.

Oesterreicher, Wulf (1997): "Zur Fundierung von Diskurstraditionen", in: Frank, B./Haye, T./Tophinke, D. (eds.), Gattungen mittelalterlicher Schriftlichkeit, Tübingen, Narr, 19-41.

Saussure, Ferdinand de (1916/1984): Cours de Linguistique Générale, édition critique préparée par Tullio de Mauro, (1a ed. 1972, sobre la base de la versión original de Bally, Sechehaye y Riedlinger de 1916) Paris: Payot.

Schlieben-Lange, Brigitte (1998): "Les hypercorrectismes de la scripturalité”, Cahiers de Linguistique Française 20, 255-273

Selig, Maria (1997): “Mündlichkeit' in mittelalterlichen Texten”, in: Martin-Dietrich Gleßgen/Franz Lebsanft (eds.), Alte und neue Philologie, Tübingen, Niemeyer, , 201-225.

Willems, Klaas (2005): “Die Grenzen der Ikonizität der Sprache: Saussures Konzeption des 'fait linguistique' revisited", Kodikas/Code: Ars Semeiotica, 28, 3-4, 243-272. 